\title{
Animal Models of Dry Eye: A Critical Assessment of Opportunities and Limitations
}

\section{Citation}

Barabino, Stefano, and M. Reza Dana. 2004. "Animal Models of Dry Eye: A Critical Assessment of Opportunities and Limitations." Investigative Opthalmology \& Visual Science 45 (6) (June 1): 1641. doi:10.1167/iovs.03-1055.

\section{Published Version}

10.1167/iovs.03-1055

\section{Permanent link}

http://nrs.harvard.edu/urn-3:HUL.InstRepos:34388130

\section{Terms of Use}

This article was downloaded from Harvard University's DASH repository, and is made available under the terms and conditions applicable to Other Posted Material, as set forth at http:// nrs.harvard.edu/urn-3:HUL.InstRepos:dash.current.terms-of-use\#LAA

\section{Share Your Story}

The Harvard community has made this article openly available.

Please share how this access benefits you. Submit a story.

Accessibility 


\title{
Animal Models of Dry Eye: A Critical Assessment of Opportunities and Limitations
}

\author{
Stefano Barabino ${ }^{1,2}$ and M. Reza Dana ${ }^{1}$
}

$\mathrm{D}$ ry eye syndrome, or keratoconjunctivitis sicca (KCS), affects tens of millions of people worldwide, representing one of the most common ocular diseases. ${ }^{1}$ The National Eye Institute Industry Workshop on Clinical Trials in Dry Eyes produced a classification that essentially separates dry eye syndrome into two major types: tear-deficient forms (including Sjögren's syndrome and non-Sjögren's tear-deficient) and evaporative forms. ${ }^{2}$ Recently, it has become clear that the immunopathogenesis of dry eye is complex and multifactorial. Sjögren's syndrome, which is the classic form of exocrine deficiency associated with KCS, is characterized by a chronic inflammatory infiltration of the lacrimal and salivary glands. The predominant cell type is $\mathrm{CD} 4^{+} \mathrm{T}$ cells that appear to have a defect in Fas-mediated apoptosis, thereby rendering their infiltration into exocrine tissue damaging. ${ }^{3}$ However, exactly what factors incite the infiltration of glands by $\mathrm{T}$ cells remains unknown. Recently, the observation that lacrimal gland acinar cells may express class II major histocompatibility complex (MHC) molecules, cathepsins B and D, and ribonucleoprotein particle $\mathrm{La} / \mathrm{SSB}$ proteins has provided some support (but no definitive proof) for the thesis that these cells may be involved in aberrant presentation of autoantigens, thereby potentially capable of priming autoreactive T cells. ${ }^{4}$

But the pathogenic mechanisms in dry eye are not limited to those involved in lacrimal inflammation. Indeed, interruption of neuronal stimulation for tear secretion, defects in transmembrane and secretory mucin expression, and Meibomian gland dysfunction can all lead to various forms of KCS. ${ }^{2}$ Numerous animal models have been developed to reflect the multiplicity of pathophysiologic mechanisms involved in KCS. Understanding the unique characteristics of these different models of dry eye, and their limitations, will provide a better insight into their use in mechanistic and therapeutic study design.

\section{Classification of Dry Eye Animal Models}

\section{Lacrimal Insufficiency}

Lacrimal Inflammatory Models: Sjögren's Syndromelike. Several animal models of Sjögren's syndrome have been developed, with particular attention to the early activation and infiltration of autoreactive lymphocytes.

Mouse Models. Lacrimal inflammation (dacryoadenitis): The nonobese diabetic (NOD) mouse model shows a lymphocytic infiltration of predominantly $\mathrm{CD} 4^{+}$Th1 cells in

From the ${ }^{1}$ Schepens Eye Research Institute and Massachusetts Eye and Ear Infirmary, Department of Ophthalmology, Harvard Medical School, Boston, Massachusetts; and the ${ }^{2}$ Department of Neurology, Ophthalmology, and Genetics, University of Genoa, Genoa, Italy.

Submitted for publication September 24, 2003; revised January 9 and February 12, 2004; accepted February 20, 2004.

Disclosure: S. Barabino, None; M.R. Dana, None

Corresponding author: M. Reza Dana, Department of Ophthalmology, Harvard Medical School, 20 Staniford Street, Boston, MA 02114; dana@vision.eri.harvard.edu. the lacrimal gland as well as other organs, including the pancreas, submandibular, and thyroid glands. Male NOD mice show significant inflammatory lesions of the lacrimal gland from the age of 8 weeks, whereas female NOD mice do not show any changes until 30 weeks of age. ${ }^{5}$ Although the incidence of diabetes and sialoadenitis in NOD females is higher than that in males, Takahashi et al. $^{5}$ have reported a significantly higher incidence of dacryoadenitis in males at all ages. Moreover, they have shown that testosterone increases the incidence of autoimmune lesions. These findings are in sharp contrast to clinical Sjögren's syndrome, which is far more prevalent in females than in males and has been associated with androgen insufficiency. In addition, although significant attention has focused on lacrimal lesions in NOD mice, the only published study in the literature demonstrating altered tear secretion in these mice reported a reduction by $33 \%$ to $36 \%$ compared with wild-type animals, ${ }^{6}$ a reduction rate that is modest compared with the profound decreased lacrimal function in Sjögren's patients. The consequences of the reduced tear production on the ocular surface epithelium of these mice have also never been definitively demonstrated. Overall, the appearance of autoimmune diabetes before autoimmune exocrinopathy in the NOD mouse suggests that it is an excellent model of secondary, but not primary, Sjögren's syndrome.

However, the immunopathogenic mechanisms involved in the NOD mouse are complex. For example, Robinson et al. ${ }^{7}$ have demonstrated that NOD.B10.H2 ${ }^{\mathrm{b}}$ mice, in which the $\mathrm{I}-\mathrm{A}^{\mathrm{g} 7}$ segment of the $\mathrm{MHC}$ region has been replaced by the $\mathrm{H} 2^{\mathrm{b}}$ haplotype of $\mathrm{C} 57 \mathrm{Bl} / 6$ mice, do not have autoimmune diabetes, but these congenic animals retain the characteristic feature of lymphocytic infiltration and dysfunction of the lacrimal gland. Therefore, it has been postulated that the appearance of $\mathrm{T}$ cells in the exocrine tissue, despite the lack of a corresponding insulitis, supports the concept that NOD mice have two independent autoimmune mechanisms, potentially rendering the NOD.B10.H $2^{\mathrm{b}}$ mouse a better model for primary Sjögren's syndrome.

The MRL/MpJ-fas ${ }^{+} / \mathrm{fas}^{+}(\mathrm{MRL} /+)$ and MRL/MpJ-fas ${ }^{l p r} / f a s^{l p r}$ (MRL/lpr) mouse models of Sjögren's syndrome exhibit lacrimal gland infiltrates characterized by a predominance of $\mathrm{CD}^{+}$ T cells. ${ }^{3}$ In contrast to the NOD model, the extent of the lacrimal gland inflammation is significantly greater in lacrimal glands of female MRL/+ and MRL/lpr mice than is observed in males, ${ }^{8}$ resembling the difference observed in human Sjögren's syndrome. Of note, in the MRL/lpr mouse the lacrimal gland inflammation has an earlier onset ( 1 month of age) and a greater severity at same ages as in the MRL/+ mice (onset at 3 months), indicating that the $l p r$ (lymphoproliferation) mutation accelerates, rather than causes the disease. ${ }^{3}$ The defective lymphocyte apoptosis (thought to regulate $\mathrm{T}$ cells reactivity naturally) in MRL/lpr mice due to an $l p r$ mutation in a single autosomal recessive gene controlling the Fas antigen occurs systemically and outside the lacrimal gland, and therefore is not itself due to the microenvironment of the lacrimal gland in this mouse model. ${ }^{9}$ According to Toda et al. ${ }^{8}$ the $l p r$ gene itself does not cause severe immunopathologic lesions in the lacri- 
mal tissue, since male $\mathrm{C} 3 \mathrm{H} / \mathrm{lpr}$ and gld (generalized lymphoproliferative disease) mice show almost no lymphocyte accumulation in the lacrimal gland. These findings seem to support the hypothesis that Fas antigen and Fas ligand are not critical gender- and strain-independent determinants of autoimmunity in lacrimal tissue. The immunopathology of this model is unique, in that the predominance of IL- 4 and B7-2 within the lacrimal gland lesions of MRL/lpr mice ${ }^{10}$ suggest a largely Th2-type response, distinct from that in the NOD model. Overall, these data suggest the existence of potentially divergent immunopathogenic mechanisms to lacrimal autoimmunity in the mouse.

Autoimmune phenomena in F1 hybrids of New Zealand Black and New Zealand White (NZB/NZW F1) mice are comparable to MRL/lpr mice and are similarly more severe in females than in males, ${ }^{8}$ but lesions in the lacrimal glands of the F1 mice become evident after only 4 months instead of 1 month. ${ }^{3}$ The effect of lacrimal inflammation on the ocular surface of these mice is poorly described. In fact, Gilbard et al. ${ }^{11}$ demonstrated the lack of corneal epithelium abnormalities in NZB/NZW F1 mice along with a normal tear film osmolarity, despite the lacrimal gland infiltration, emphasizing the important point that lacrimal and ocular surface disease do not necessarily correlate.

There are several other murine models that are also associated with a predominant $\mathrm{CD}^{+}{ }^{+} \mathrm{T}$ lymphocyte infiltration of the lacrimal gland. The TGF- $\beta 1$ knockout mouse, for example, has shown significant inflammatory cell infiltrates in the lacrimal gland between the ages of 2 and 4 weeks, whereas the globe itself exhibits a normal structure and phenotype on histologic examination. ${ }^{12}$ Unfortunately, shortly after weaning, the mice begin to show the symptoms of a wasting syndrome and die between 3 and 4 weeks. Providing liquid diet supplements at the time of weaning prolongs survival of TGF- $\beta 1$ knockout mouse almost twice as long as providing standard hard chow, thus enabling longer observation of these mice. ${ }^{13}$ The shortened life of the TGF- $\beta 1$ knockout mouse generally complicates their use as a model, particularly for studies involving testing of therapeutics.

Mice homozygous for an autosomal recessive mutation, alymphoplasia (aly), which causes a systemic absence of lymph nodes and Peyer's patches, have also been demonstrated to have infiltration of $\mathrm{CD}^{+}{ }^{+} \mathrm{T}$ cells into their lacrimal and salivary glands, lung, liver, kidney, and pancreas, ${ }^{14}$ potentially serving as a model of Sjögren's syndrome. In particular, lymphocytic infiltrates can be detected in the lacrimal gland from the age of 14 weeks in both males and females. Several factors complicate the use of these mice for study of ocular surface disease. First, no definitive data have been produced relating the lacrimal gland infiltration to altered tear secretion in these mice. Second, the absence of lymph nodes, together with a variety of other serious immune defects, including depressed baseline immunoglobulin production and isotypeswitching, defective $\mathrm{T}$ cell function, and faulty homing responses, all confound the study of the effect of lacrimal insufficiency on the eye, as each of these factors alone or in combination may affect the cornea and ocular surface.

Finally, the IQI/Jic has recently been established as a new mouse model for primary Sjögren's syndrome. Unlike the NOD model, in the IQI/Jic mouse the lymphocytic infiltration is well restricted to salivary and lacrimal glands. Konno et al. ${ }^{15}$ have suggested that in this model, the early phase of adenitis is mediated by dendritic cells that promote induction of Th1-type immunity, which may also be potentiated by lacrimal epithelial cells that also function as secondary antigen-presenting cells (APCs). The general phenotype of this mouse model of Sjögren's syndrome makes it quite attractive for the study of the early phases of the disease, even if the development of complete dacryoadenitis at an advanced age ( 9 months) makes it economically unattractive. Another attractive model for inducing salivary and lacrimal gland specific lymphocytic infiltration, but at a more rapid pace, has been developed by injecting mononuclear cells isolated from the inflamed submandibular salivary tissues of MRL/lpr mice intraperitoneally into Scid mice. At 8 weeks after the injection, these Scid mice exhibit inflammatory lesions in the salivary and lacrimal glands, but not in other organs, confirming the tissue-specificity of disease in these animals. Of interest, the injection of lymphocytes from the spleen of the MRL/lpr mice have not produced any inflammatory lesions in Scid mice. ${ }^{16}$

Autoantibodies: Human Sjögren's syndrome is characterized by the presence of serum autoantibodies to the ribonucleoprotein particles SS-A (anti-SS-A/Ro, $52 \mathrm{kDa}$; anti-SS-A/Ro, $60 \mathrm{kDa}$ ) and SS-B (anti-SS-B/La), ${ }^{17}$ and, as recently demonstrated, anti-120-kDa $\alpha$-fodrin, ${ }^{18}$ and anti-M3 and -M1 muscarinic acetylcholine receptors. ${ }^{19}$ Autoantibodies are also present in the serum of NOD and MRL/lpr mice, but with a different pattern of expression (Fig. 1) than what is observed in humans. The role of autoantibodies in NOD mouse has been postulated based on the observation that NOD $\operatorname{Ig} \mu^{\text {null }}$ mice (lacking B lymphocytes) maintain normal secretory function, even in the presence of focal infiltrates in the salivary gland, suggesting that humoral immunity plays a critical role in the pathogenesis of autoimmunity in these animals. ${ }^{20}$ Furthermore, the infusion of anti-M3 muscarinic receptor antibodies into NOD-Scid mice produces a decreased salivary response. ${ }^{21}$ To date, there have been no published data about the influence of anti-M3 muscarinic receptor antibodies on tear production.

Finally, NFS/sld mice thymectomized at 3 days of age (3d-Tx NFS/sld) have also been used as a model of primary Sjögren's syndrome to identify the autoantigen 120 -kDa $\alpha$-fodrin. ${ }^{18}$ In particular, this autoantigen, purified from the salivary glands of $3 \mathrm{~d}-\mathrm{Tx}$ NFS/sld mice, postulated as the presenting antigen in salivary gland disease in Sjögren's syndrome, has been demonstrated to be the product of caspase 3 cleavage of the $240-\mathrm{kDa}$ $\alpha$-fodrin, rendering this model ideal for study of the mechanism of apoptosis in Sjögren's syndrome. However, the profound effects of the thymectomy on the endocrine-immune system limits the use of this model for long-term prospective studies.

Rabbit Models. Because of the large exposed ocular surface in rabbits compared with mice, standard dry eye clinical tests such as tear break-up time and fluorescein or rose bengal staining of the ocular surface can be much more easily performed in rabbits. Recently, Zhu et al. ${ }^{22}$ induced an autoimmune disease in rabbits resembling Sjögren's syndrome by injecting into the lacrimal gland autologous peripheral blood lymphocytes proliferated in culture with epithelial cells obtained from the contralateral excised gland. The histopathologic picture of the lacrimal glands so treated was similar to the findings in patients with Sjögren's syndrome, with predominantly $\mathrm{CD}^{+} \mathrm{T}$ cell infiltrates. A continuous decrease in tear production and stability and an increase in rose bengal staining of the ocular surface, were recorded in eyes injected with activated lymphocytes and in the contralateral lacrimal glandexcised eyes by 2 weeks, indicating a generalized autoimmune phenomenon. An important remaining point to verify in this model is whether the acinar cell preparation (the putative APCs of this model) is completely devoid of any professional bone marrow-derived APCs that can stimulate the T cells.

Rat Models. Experimental immune dacryoadenitis has been produced also in Lewis rats by sensitization with a single intradermal administration of an extract of lacrimal gland in complete Freund's adjuvant (CFA) and simultaneous intravenous injection of killed Bordetella pertussis. ${ }^{23}$ No data have been published about the effect of this procedure on the ocular surface. 
FIGURE 1. Comparison of autoantibodies in humans and the NOD and MRL/lpr mouse models and their effect on lacrimal gland secretory function. M1 R, muscarinic acetylcholine receptor 1; M3 R, muscarinic acetylcholine receptor 3. "Presence in low percentage. (Adapted from Van Blokland SC, Versnel MA. Pathogenesis of Sjögren's syndrome: characteristics of different mouse models for autoimmune exocrinopathy. Clin Immunol. 2002;103:111-124. (C) Elsevier, 2002.)

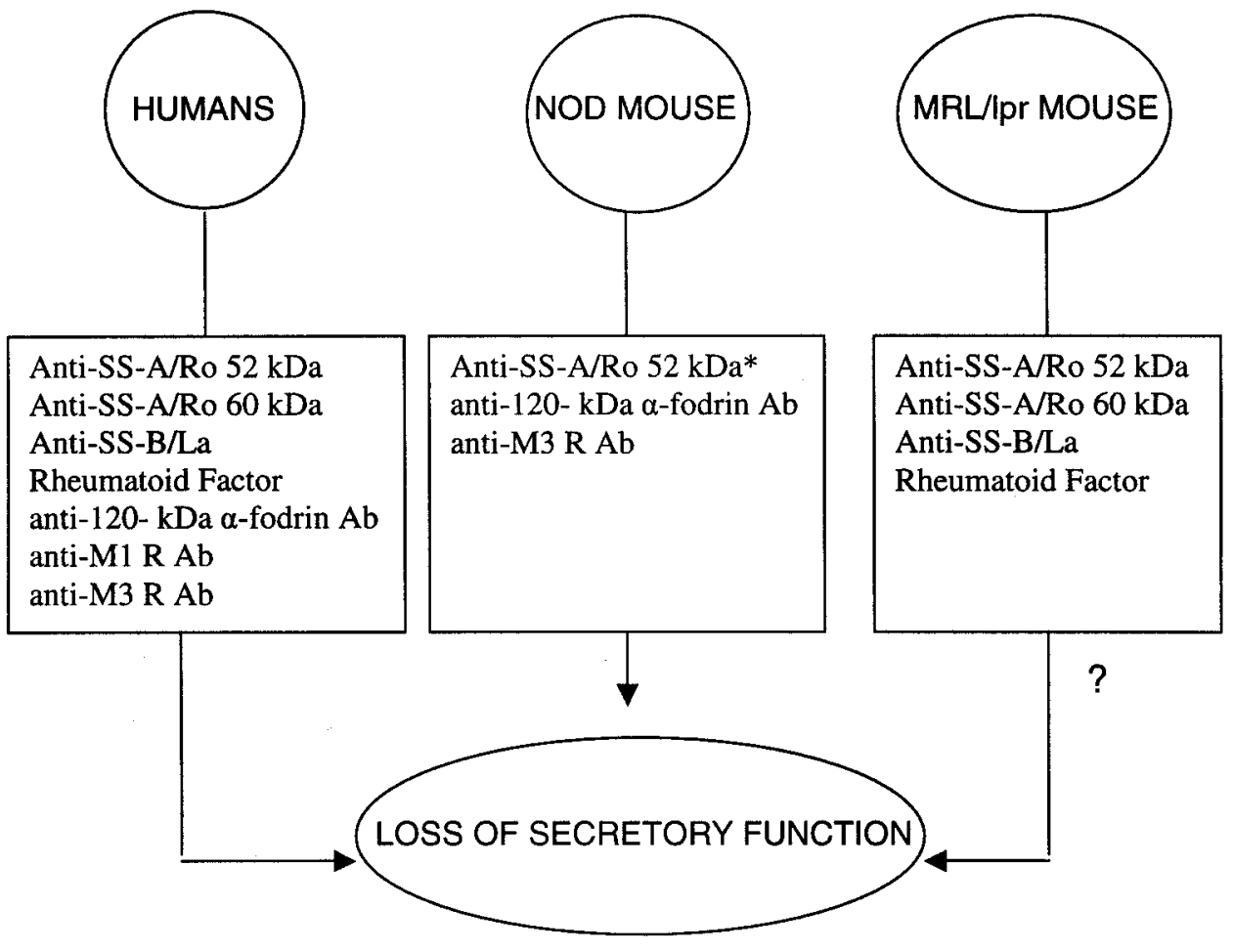

Mechanical Control of Lacrimal Secretion. In dogs, cats, rabbits, and mice the removal of the main lacrimal gland produces a decrease in basal tear production as measured by the Schirmer test, but it does not cause significant changes in ocular surface signs, even after a long follow-up. This may be due to accessory lacrimal glands that could provide an adequate compensatory tear supply. In rabbits, closing the lacrimal gland excretory duct and surgically removing the nictitating membrane and harderian gland can cause an increase in tear osmolarity at postoperative day 1 accompanied with significant decrease in conjunctival goblet cell density by 8 weeks.

Monkeys have one main lacrimal gland with an anatomic structure similar to that in humans. The removal of the lacrimal gland has been demonstrated to decrease tear secretion, but without producing any reproducible ocular surface damage. ${ }^{24}$ As in other species, it is thought that compensatory tear production by the accessory lacrimal glands alone may be sufficient to maintain a stable tear layer.

Endocrine Control of Lacrimal Secretion. To date there have been no animal models described in the literature that show spontaneous development of dry eye due to a specific endocrine imbalance. Nevertheless, orchiectomy and ovariectomy in rabbits, rats, mice, guinea pigs, and hamsters, and hypophysectomy in rats, have been used as models to study the influence of hormones on the structure and function of the lacrimal and Meibomian glands. These procedures are not meant as an exact mimic of dry eye, but to decipher important pathogenic aspects of tear film regulation. Hormones have both direct and indirect effects on exocrine tissues due to their capacity to regulate immunity as well as the gene expression of many secreted molecules. For example, Sullivan et al. ${ }^{25}$ have demonstrated that androgens regulate the function of lacrimal glands and the quantity, quality, and metabolism of the lipid layer of the tear film produced by the Meibomian glands.

There are many variables that influence hormonal effects on the lacrimal glands of animals, including their species, strain, gender, and age, to name a few. Another important aspect to consider in studies on endocrine control of lacrimal secretion is the experimental procedure itself. Hypophysectomy of female rats, for example, removes prolactin secretion and causes a significant atrophy of the lacrimal gland with deficient tear production. However, this procedure also eliminates other hormones (such as growth hormone) that regulate lacrimal gland development and function. Therefore, hypophysectomy is not indicated for studies that have the primary purpose of clarifying the influence of a single hormone on tear secretion.

Genetically modified mice are expected to aid in the study of the influence of a specific hormone(s) on the tear film homeostasis.

Neural Control of Lacrimal Secretion. As described by Stern et al. $^{26}$ the ocular surface (cornea, conjunctiva, and accessory lacrimal glands), Meibomian glands, and main lacrimal gland, are interconnected by neural reflex loops that maintain an integrated "functional unit." The only dry eye animal model described in the literature that putatively mimics a blockade of the neural reflex loops involved in maintaining the normal tear physiology has been created by administrating the anticholinergic agent atropine in New Zealand albino rabbits. The antimuscarinic effect of topical $1 \%$ atropine sulfate has been shown to reduce lacrimal secretion significantly within 2 days and to induce corneal epithelial defects by 3 days. ${ }^{27}$ Intramuscular doses of atropine are not recommended for use, because they produce toxic systemic side effects and fail to induce corneal damage.

The MLR/lpr mouse model has been used to test the hypothesis that a reduction of the quantity of parasympathetic fibers, or an alteration in the neurotransmitters in the healthy tissue of the lacrimal gland, is responsible for tear decrease in patients with Sjögren's syndrome. Zoukhri et al. ${ }^{28}$ have shown, however, that in the MRL/lpr model, parasympathetic, sympathetic, and sensory innervations of the lacrimal gland are not altered and the $\mathrm{Ca}^{2+}$ signaling portion of cholinergic nerve transmission is indeed upregulated with the onset of lymphocytic infiltration in these mice, suggesting that inadequate 
TABLE 1. Mutant and Transgenic Mice with Meibomian Gland Abnormalities

\begin{tabular}{|c|c|c|c|c|c|}
\hline Ocular Lesion & Symbol* & CHR & Gene Name & Allele Name & Other Lesions \\
\hline \multirow[t]{4}{*}{$\begin{array}{l}\text { Meibomian gland } \\
\text { aplasia }\end{array}$} & Edaradd $^{\mathrm{cr}}$ & 13 & EDAR-associated death domain & Crinkled & $\begin{array}{l}\text { Common features to all } \\
\text { Meibomian gland aplasia: No } \\
\text { hair on tails, no sweat glands, } \\
\text { dental abnormalities }\end{array}$ \\
\hline & $E d a r^{\mathrm{dl}-\mathrm{j}}$ & 10 & Ectodysplasin-A receptor & Downless & \\
\hline & $E d a^{\mathrm{Ta}}$ & $\mathrm{X}$ & Ectodysplasin-A & Tabby & \\
\hline & & & $\begin{array}{l}\text { Tumor necrosis factor receptor- } \\
\text { associated factor } 6\end{array}$ & TRAF6 deficiency & \\
\hline \multirow{2}{*}{$\begin{array}{l}\text { Meibomian gland } \\
\text { hypoplasia }\end{array}$} & $S c d 1^{\mathrm{ab}-\mathrm{j}}$ & 19 & Stearoyl-coenzyme A desaturase 1 & Asebia & Alopecia, scaly skin \\
\hline & Dgat1 & 15 & Diacylglicerol $O$-acyltransferase 1 & Dgat & \\
\hline \multirow{2}{*}{$\begin{array}{l}\text { Meibomian gland } \\
\text { atrophy }\end{array}$} & Soat1 & 1 & Sterol $O$-acyltransferase 1 & & Cutaneous, xanthomatosis \\
\hline & APOC1 & UN & Apolipoprotein $\mathrm{Cl}$ & Transgenic & Hair loss, scaly skin \\
\hline \multirow{2}{*}{$\begin{array}{l}\text { Meibomian } \\
\text { ductal ectasia }\end{array}$} & $\mathrm{Hr}$ & 14 & Hairless & & \\
\hline & Odc & 12 & Ornithine decarboxylase & Transgenic & $\begin{array}{l}\text { Loss of body hair, enlargement of } \\
\text { skin mass, excessive nail } \\
\text { growth }\end{array}$ \\
\hline
\end{tabular}

* The Jackson Laboratory (Bar Harbor, ME) nomenclature. CHR, chromosome; EDAR, ectodysplasin-A receptor; UN, unknown.

innervation of exocrine tissue alone cannot explain the partial deficit in lacrimation in Sjögren's syndrome.

\section{Evaporative Dry Eye}

The tear film is constantly exposed to multiple environmental factors, including variable temperatures, airflow, and humidity, which may stimulate or retard its evaporation. The lipids produced by the Meibomian glands and spread onto the aqueous phase by the shear forces produced by each blink, protect the tear film from excessive evaporation. Short-term models for hyperevaporative dry eye have been created by preventing rabbits from blinking through placement of lid specula or sutures. After 2 hours of desiccation induced by lid specula, dry spots appear on the rabbit corneal epithelial surface and stain with methylene blue. ${ }^{29}$ Because of the acuteness of the induced dry eye and the use of anesthetics (which themselves can decrease tear secretion), these models are not optimal for studying KCS pathogenesis, which is a chronic event. However, in these rabbits, corneal epitheliopathy develops within a few hours, and hence such rabbits can be used to evaluate the effect of artificial tears or other therapies aimed at delaying the evaporative loss of the preocular tear film.

Histopathologic and clinical studies indicate that Meibomian gland duct orifice closure is a characteristic feature of meibomitis-related dry eye, as seen clinically in multiple disease settings, including ocular rosacea. The first objective evidence in support of this hypothesis was provided by Gilbard JP et al. ${ }^{30}$ who used a rabbit model in which the Meibomian gland orifices were individually closed by cauterization. They demonstrated not only a significant decrease in conjunctival goblet cell density and corneal epithelial glycogen levels by 12 weeks, but also the presence of inflammatory cells within the bulbar conjunctiva after 20 weeks. Although this model is an interesting one for studying the effect of Meibomian gland dysfunction on the ocular surface, this is best done in a controlled environment in which temperature, humidity, and airflow are constantly monitored and controlled. This would more closely reflect the clinical setting, where it has been demonstrated that the tear film evaporation rate from the ocular surface is temperature-, humidity-, and airflow-dependent. ${ }^{31}$ Recently, several novel mouse models of Meibomian gland dysfunction have been created (Table 1). These models provide new insights into the pathophysiologic mechanisms of hyperevaporative dry eye and identify potential novel gene therapy targets.

\section{Combined Lacrimal Insufficiency and Evaporative Dry Eye Models}

Dursun et al. ${ }^{32}$ have presented a mouse model of KCS in which transdermal scopolamine application and exposure to a continuous airflow are used to induce dry eye in female mice. The function of scopolamine is to induce a pharmacologic blockade of cholinergic (muscarinic) receptors in the lacrimal gland and therefore to decrease aqueous production, whereas the airflow is to mimic environmental stressing conditions (with resultant increased evaporation). Alterations to aqueous tear production and volume, tear clearance, corneal barrier function, conjunctival morphology and goblet cells density, resemble those of human KCS. However, the tear production has been shown to be reduced only in the group of mice treated with scopolamine, whereas the airflow does not appear to influence the tear film and ocular surface signs. Although there are significant benefits to studying sicca-related ocular surface disease in mice that do not have concomitant systemic immune dysfunction, this model has yet to be optimized, as it does not adequately control important environmental factors such as temperature and humidity-important factors that can have profound effects on the exposed ocular surface. Moreover, the airflow generated by an air fan placed 6 in. in front of the mice's cage for 10 hours a day for 12 consecutive days may be a source of stress for mice and therefore influence the data on the tear film homeostasis. We believe this model to resemble most the neural inhibition of tear secretion through pharmacologic inhibition of cholinergic pathways more than a "pure" hyperevaporative dry eye model.

\section{Spontaneous KCS in Dogs}

Quimby in 1979 first recognized the similarities between the dogs with severe KCS, xerostomia, vaginal dryness, and multiple serum antibodies and Sjögren's syndrome in humans. This likeness has been confirmed lately by a study of lacrimal glands and conjunctiva in KCS dogs by TUNEL assay, revealing a decrease in apoptosis in the lymphocytes infiltrating the lacrimal gland and an increase in apoptosis in lacrimal acinar and conjunctival epithelial cells. ${ }^{33}$ The spontaneous canine dry eye 
model has been widely used to develop therapeutic interventions for both veterinary and clinical populations, as exemplified by trials on topical application of cyclosporin A. ${ }^{33}$ The incidence of KCS in the general canine population is unknown, although in one study of $460 \mathrm{dogs}$, the prevalence was estimated at $35 \%$, with particular predisposition among aged dogs of either sex. The breed with the highest relative prevalence of KCS is the American cocker spaniel (20.6\%), whereas the commonly used laboratory dogs such as mixed-breed and beagle dogs have lower prevalence rates of $11.5 \%$ and $1.2 \%$, respectively. ${ }^{34}$ Even if there are multiple causes of canine KCS (e.g., distemper virus, drug-induced), most are of undetermined origin and may be immune mediated. Spontaneous KCS in dogs provides a very useful model for dry eye studies: the large size of the dog's globe compared with that of the mouse provides benefits for ocular surface diagnostic tests, as well as collection and study of tears and mucin, which is difficult in small rodents. Negative aspects of this model include the outbred source of most dogs, their maintenance costs, and potential difficulties with receipt of animal care and use committee approval for experimental procedures on this species. Finally, it must also be emphasized that signs of dry eye tend to be considerably more severe in dogs than those in humans. Hypertrophic and hyperemic conjunctiva, mucous filaments, and a thick tenacious mucopurulent ocular discharge, corneal vascularization, corneal melanosis, and recurrent ulcers, are not infrequent in canine dry eye.

\section{Conclusion}

The existing animal models of dry eye mimic different pathogenic mechanisms of KCS, but at the moment none of them seems to mirror precisely the complexity and chronicity of this frequent and debilitating condition. Despite their small size, the advanced murine immunogenetics and extensive availability of reagents and knockout and transgenic strains make the mouse a very attractive model. Further studies incorporating both intrinsic (immune, endocrine, neuronal) and extrinsic (environmental) factors in dry eye pathogenesis in the mouse will offer important advances in the field.

\section{References}

1. Schaumberg DA, Sullivan DA, Buring JA, Dana MR. Prevalence of dry eye syndrome among US women. Am J Opbthalmol. 2003; 136:318-326.

2. Lemp MA. Report of the National Eye Institute/Industry workshop on clinical trials in dry eyes. CLAO J. 1995;21:221-232.

3. Van Blokland SC, Versnel MA. Pathogenesis of Sjögren's syndrome: characteristics of different mouse models for autoimmune exocrinopathy. Clin Immunol. 2002;103:111-124.

4. Yang T, Zeng H, Zhang J. MHC class II molecules, cathepsins, and $\mathrm{La} / \mathrm{SSB}$ proteins in lacrimal acinar cell endomembranes. Am J Pbysiol. 1999;277:C994-C1007.

5. Takahashi M, Ishimaru N, Yanagi K, Haneji N, Saito I, Hayashi Y. High incidence of autoimmune dacryoadenitis in male non-obese diabetic (NOD) mice depending on sex steroid. Clin Exp Immunol. 1997;109:555-561.

6. Humphreys-Beher MG, Hu Y, Nakagawa Y, Wang PL, Purushotham KR. Utilization of the non-obese diabetic (NOD) mouse as an animal model for the study of secondary Sjögren's syndrome. Adv Exp Med Biol. 1994;350:631-636.

7. Robinson CP, Yamachika S, Bounous DI, et al. A novel NODderived murine model of primary Sjögren's syndrome. Arthritis Rbeum. 1998;41:150-156.

8. Toda I, Sullivan BD, Rocha EM, Da Silveira LA, Wickham LA, Sullivan DA. Impact of gender on exocrine inflammation in mouse models of Sjögren's syndrome. Exp Eye Res. 1999;69:355-366.
9. Jabs DA, Lee B, Whittum-Hudson J, Prendergast RA. The role of Fas-Fas ligand-mediated apoptosis in autoimmune lacrimal gland disease in MRL/MpJ mice. Invest Opbthalmol Vis Sci. 2001;42: 399-401.

10. Jabs DA, Lee B, Whittum-Hudson JA, Prendergast RA. Th1 versus Th2 immune responses in autoimmune lacrimal gland disease in MRL/Mp mice. Invest Ophthalmol Vis Sci. 2000;41:826-831.

11. Gilbard JP, Hanninen LA, Rothman RC, Kenyon KR. Lacrimal gland, cornea, and tear film in the NZB/NZW $\mathrm{F}_{1}$ hybrid mouse. Curr Eye Res. 1987;6:1237-1248.

12. McCartney-Francis NL, Mizel DE, Frazier-Jessen M, Kulkarni AB, McCarthy JB, Wahl SM. Lacrimal gland inflammation is responsible for ocular pathology in TGF- $\beta 1$ null mice. Am J Patbol. 1997;151: 1281-1288.

13. McCartney-Francis NL, Mizel DE, Redman RS, et al. Autoimmune Sjögren's-like lesions in salivary glands in TGF- $\beta 1$-deficient mice are inhibited by adhesion blocking peptides. J Immmunol. 1996; 157:1306-1312.

14. Tsubata R, Tsubata T, Hiai H, et al. Autoimmune disease of exocrine organs in immunodeficient alymphoplasia mice: a spontaneous model for Sjögren's syndrome. Eur J Immunol. 1996;26:27422748.

15. Konno A, Takada K, Saegusa J, Takiguchi M. Presence of B7-2 dendritic cells and expression of Th1 cytokines in the early development of sialodacryoadenitis in the IQI/Jic mouse model of primary Sjögren's syndrome. Autoimmunity. 2003;36:247254 .

16. Hayashi Y, Haneji N, Hamano H, Yanagi K. Transfer of Sjögren's syndrome-like autoimmune lesions into SCID mice and prevention of lesions by anti-CD 4 and anti-T cell receptor antibody treatment. Eur J Immunol. 1994;24:2826-2831.

17. Wharen M, Solomin L, Pettersson I, Isenberg D. Autoantibodies repertoire to Ro/Ssa and La/SSB antigen in patients with primary and secondary Sjögren's syndrome. J Autoimmun. 1996;9:537544.

18. Ulbricht $\mathrm{K}$, Schmidt RE, Witte T. Antibodies against $\alpha$-fodrin in Sjögren's syndrome. Autoimmun Rev. 2003;2:109-113.

19. Bacman S, Berra A, Sterin-Borda L, Borda E. Muscarinic acetylcholine receptor antibodies as a new marker of dry eye Sjögren syndrome. Invest Ophthalmol Vis Sci. 2001;42:321-327.

20. Robinson CP, Brayer J, Yamachika S, et al. Transfer of human serum IgG to nonobese diabetic $\operatorname{Ig} \mu^{\text {null }}$ mice reveals a role for autoantibodies in the loss of secretory function of exocrine tissues in Sjögren's syndrome. Proc Natl Acad Sci USA. 1998;95:75387543.

21. Nguyen KH, Brayer J, Cha S, et al. Evidence for antimuscarinic acetylcholine receptor antibody-mediated secretory dysfunction in NOD mice. Arthritis Rbeum. 2000;43:2297-2306.

22. Zhu Z, Stevenson D, Schechter JE, Mircheff AK, Atkinson R, Trousdale MD. Lacrimal histopathology and ocular surface disease in a rabbit model of autoimmune dacryoadenitis. Cornea. 2003;22:2532.

23. Liu SH, Prendergast RA, Silverstein AM. Experimental autoimmune dacryoadenitis. I. Lacrimal gland disease in the rat. Invest Opbthalmol Vis Sci. 1987;28:270-275.

24. Maitchouk DY, Beuerman RW, Ohta T, Stern M, Varnell RJ. Tear production after unilateral removal of the main lacrimal gland in squirrel monkeys. Arch Ophthalmol. 2000;118:246-252.

25. Sullivan DA, Sullivan BD, Evans JE, et al. Androgen deficiency, meibomian gland dysfunction, and evaporative dry eye. Ann NY Acad Sci. 2002;966:211-222.

26. Stern ME, Beuerman RW, Fox RI, Gao J, Mircheff AK, Pflugfelder SC. The pathology of dry eye: the interaction between the ocular surface and lacrimal glands. Cornea. 1998;17:584-589.

27. Burgalassi S, Panichi L, Chetoni P, Saettone MF, Boldrini E. Development of a simple dry eye model in the albino rabbit and evaluation of some tear substitutes. Opbthalmic Res. 1999;31:229235 .

28. Zoukhri D, Hodges RR, Dartt DA. $\mathrm{Ca}^{2+}$ signaling by cholinergic and $\alpha_{1}$-adrenergic agonists is up-regulated in lacrimal and submandibular glands in a murine model of Sjögren's syndrome. Clin Immunol Immunopatbol. 1998;89:134-140. 
29. Fujihara T, Nagano T, Nakamura M, Shirasawa E. Establishment of a rabbit short-term dry eye model. J Ocul Pharmacol Ther. 1995; 11:503-508.

30. Gilbard JP, Rossi SR, Heyda KG. Tear film and ocular surface changes after closure of the meibomian gland orifices in the rabbit. Ophthalmology. 1989;96:1180-1186.

31. Rolando M, Refojo MF. Tear evaporimeter for measuring water evaporation rate from the tear film under controlled conditions in humans. Exp Eye Res. 1983;36:25-33.
32. Dursun D, Wang M, Monroy D, et al. A mouse model of keratoconjunctivitis sicca. Invest Ophthalmol Vis Sci. 2002;43:632-638.

33. Gao J, Schwalb TA, Addeo JV, Ghosn CR, Stern ME. The role of apoptosis in the pathogenesis of canine keratoconjunctivitis sicca: the effect of topical cyclosporin A therapy. Cornea. 1998;17:654663.

34. Kaswan R, Pappas C Jr, Wall K, Hirsch SG. Survey of canine tear deficiency in veterinary practice. Adv Exp Med Biol. 1998;438:931-939.

\section{New Developments in Vision Research}

Written for a broad audience, the articles in this column succinctly and provocatively review a rapidly changing area of visual science that shows progress and holds potential. Authors and topics are chosen by the Editor-in-Chief in collaboration with the Editorial Board.

To avoid bias, the Editor-in-Chief subjects these articles to the same rigorous peer review process to which all other IOVS articles are subjected. Space and reference limitations are imposed on the authors.

The purpose of this series is not the recognition of individual scientists, nor exhaustive review of a subject, but the stimulation of interest in a new research area. 